\title{
Workshop on Instructional Skills in the Clinical Setting
}

\author{
Jennifer Prekeges, CNMT, FSNMMI-TS \\ Nuclear Medicine Technology Department, Bellevue College, Bellevue, Washington
}

This article describes a workshop offered annually by the radiation and imaging programs at Bellevue College, Bellevue, WA. The workshop provides an educator perspective to those who teach students in the college's clinical internships. An outline of the workshop is given in this article, as are the reasons for its ongoing success.

Key Words: clinical instruction; learning styles; evaluation methods

J Nucl Med Technol 2018; 46:96-98

DOI: 10.2967/jnmt.118.209213

\section{A}

llied health educational programs rely on clinical professionals to teach students. But these professionals may not be trained in the educational process. They may not know about learning styles or how to provide meaningful evaluations. They did not necessarily expect to take on the role of instructor when they entered their health-care profession. At my institution, we have addressed this issue by offering an annual day-long workshop titled "Instructional Skills in the Clinical Setting."

The workshop was originally developed some 20 years ago by the clinical coordinator for the radiation therapy program of Bellevue College, Bellevue, WA, in response to concerns raised in the accreditation process. Over time, it has morphed into presentations by faculty from the entry-level radiation and imaging programs: radiologic technology, nuclear medicine technology, radiation therapy, and diagnostic ultrasound. Technologists are invited from all hospitals and clinics that host Bellevue College students. This article outlines the topics covered in the workshop.

\section{LOGISTICS}

The workshop is offered on a Saturday from 8:30 AM to $4 \mathrm{PM}$ and awards $6 \mathrm{~h}$ of ASRT-approved continuing education. For a fairly nominal fee of $\$ 25$ per person, participants receive handouts for each session, lunch, morning and afternoon snacks, and beverages. The first 2 speakers

Received Feb. 1, 2018; revision accepted Mar. 14, 2018.

For correspondence or reprints contact: Jennifer L. Prekeges, Bellevue

Community College, 3000 Landerholm Circle S.E., Bellevue, WA 98007.

E-mail: jennifer.prekeges@bellevuecollege.edu

Published online Mar. 29, 2018.

COPYRIGHT (c) 2018 by the Society of Nuclear Medicine and Molecular Imaging. present in the morning and the third and fourth after lunch. The workshop ends with a video montage of students from each program expressing their appreciation to their clinical instructors. The workshop is advertised to Bellevue College's own clinical partners and to other associatelevel and bachelor-level allied health programs in the institution.

\section{WORKSHOP OBJECTIVES}

The overall goals of the workshop are to describe the multiple aspects of the clinical instructor role, discuss how student learning styles and preferences can be used to advantage in clinical instruction, implement a variety of evaluation tools and formats, demonstrate helpful ways to provide feedback and encouragement, and discuss common issues that arise in clinical instruction and ways to address them.

The 4 presentations are entitled, "Dimensions of Clinical Learning," "Approaches to Learning," "Evaluation Techniques," and "Common Clinical Issues." Each is briefly summarized below, along with the participants' reactions to the presentations.

\section{DIMENSIONS OF CLINICAL LEARNING}

The workshop begins with an overview of the roles of the clinical instructor, which include coach, mentor, exemplar of good clinical practice, and disciplinarian. The opening exercise asks those present to recall their own days as students and to name the characteristics of their favorite clinical instructor. This exercise reminds these professionals of their own route to competence and contrasts their current high level of expertise to their students' stilldeveloping skills. Short videos are used to illustrate this gap, giving the clinical instructors a sense of empathy for the students. This session is also used to communicate important legal aspects of the educator role (supervision, Health Insurance Portability and Accountability Act/Family Educational Rights and Privacy Act, sexual harassment).

The clinical instructor has a unique role that impacts student learning in ways both obvious and subtle, and simple gestures are often the ones that make the most difference. The research presented by Knight in this issue of the Journal of Nuclear Medicine Technology (1) illuminates key personal aspects of being a clinical instructor. Information from the presentation by Knight at the 2017 
annual meeting of the Society of Nuclear Medicine and Molecular Imaging was incorporated by the speaker for last fall's workshop, and this content was well received by those present. The speaker outlined factors that motivate students to do well and factors that demotivate students. The finding that student-clinical instructor interpersonal interactions are key to student motivation seemed to resonate with the attendees.

Another set of concepts covered in this presentation is the progression from novice to expert and the potential for an "expert blind spot" that can block the student's understanding. The learning process can be described as progressing from unconscious incompetence (lack of awareness of the scope of knowledge required) to conscious incompetence (awareness of the scope of knowledge still to be learned) to conscious competence (possession of knowledge but needing conscious thought) to, finally, unconscious competence (ability to perform without requiring conscious thought) (2). Gaining an understanding of themselves as experts who have unconscious competence, and their students as still in the early stages of gaining competence, provides attendees with a perspective that many have not previously understood. This perspective, in turn, helps them to become better instructors.

\section{APPROACHES TO LEARNING}

The second part of the workshop is the most theoretic. "Approaches to Learning" addresses 3 understandings of brain function and differences in learning preferences. The first is the left-brain-right-brain dichotomy. Although most students can use both sides of their brains well under normal circumstances, clinical instructors need to be aware that when under stress, most of us tend to work in our preferred brain hemisphere. Those who are naturally leftbrained tend to become more analytic and dispassionate, whereas those who are naturally right-brained may tend to become more global and emotional.

Second, a 4-quadrant theory of preferred learning styles is reviewed. There are actually several versions of this construct $(3,4)$, which can be summarized as theorists (preferring to understand big-picture concepts), pragmatists (preferring to have step-by-step instructions), activists (preferring to learn by doing), and reflectors (preferring to learn through understanding feelings). Awareness of an individual student's preferred learning style provides insight that improves the student-clinical instructor interaction and ultimately the level of student success.

The third understanding of how students learn is whether they have a preference for taking in visual, auditory, or kinesthetic information. Although most people can learn easily when presented with any of these 3 types of information, a student who needs a particular kind of input will struggle when that kind of input is not available. In this section, as in the previous two, examples are provided of students whose learning styles were problematic to the process of clinical instruction, illustrating that an understanding of the learning style contributes to a better outcome for the student.

The workshop audience generally expresses appreciation for the increased understanding of the varieties of learning styles. Learning is enhanced by supplying time and tools to allow audience members to identify their own learning styles. This presentation is the most content-heavy, which tends to lead to more mixed reviews, but the opportunity for attendees to use these tools to find their own preferences is often a high point of the workshop.

\section{EVALUATION TECHNIQUES}

Evaluation of student progress is a topic that educators know well but is generally beyond the scope of clinical practice. This presentation provides an understanding of the types of evaluations, the rationale for each, and the ways these can be used in assessment of student accomplishments. The session is designed to allow attendees to separate into modality-specific groups and review the evaluation tools that are used within each program. The clinical instructors benefit from the opportunity to hear how the evaluations are used by the programs, and the programs benefit from the clinical instructors' feedback. It is not uncommon for a program to make a change based on feedback received at the workshop.

One emphasis in this talk is on how to give feedback in a way that is positive for both student and clinical instructor. The presenter talks about the need to be specific in communicating expectations early in a clinical rotation, so that the end-of-term evaluation is not the first time these expectations are brought up. Although no student ever likes to receive criticism, it is the only way to mold a student into a good technologist, and giving criticism early allows the student to show improvement over the course of the evaluation period. The presentation provides examples of past evaluation comments, both helpful and unhelpful, to give the clinical instructors a better sense of how these come across to the student.

\section{COMMON CLINICAL ISSUES}

The final presentation in the workshop is on issues that commonly arise with students in clinical internships, including inappropriate behavior, communication difficulties, and a lack of professionalism. This session is again filled with examples from the instructors' own experiences with students. These might include a student disrupting the workplace daily on arrival, a "helicopter student" trying to learn everything but not doing anything on his or her own, and a student engaging in departmental gossip. Recently, the presenter added a discussion of younger students' perceived "deficiencies" compared with older generations, such as their dependence on their phones and their need for positive feedback, and how to handle these behaviors in the clinical setting. 
The discussion of different generations, and how each adjusts to the clinical setting, evolves each year as the audience changes. This year, when the presenter suggested that Millennials highly value collaboration, the Millennials in the audience immediately validated this statement and gave their own examples of collaboration, either as students themselves or in their clinical work with students. The entire group benefits from the perspective that can be offered by each attendee, allowing all involved in the workshop to learn from each other.

\section{CONCLUSION}

Attendees generally respond positively to the individual presentations, the opportunity to interact with and make suggestions to the program faculty, and the broader perspective they gain from the presentations and from other clinical instructors. The success of the workshop results from a couple of intentional decisions. One is the use of real-life examples. This makes the workshop relevant to the attendees. The other is incorporation of plenty of time and space for audience participation. There are opportunities for increased understanding of oneself, discussion of teaching techniques, and troubleshooting of situations that have been encountered. In the big picture, the more familiar clinical instructors are with the educational process, the better they will be able to educate students to become good technologists.

\section{DISCLOSURE}

No potential conflict of interest relevant to this article was reported.

\section{REFERENCES}

1. Knight AW. How the behavior of clinical instructors affects clinical engagement of students from a motivational perspective. J Nucl Med Technol. 2018; 46:99-106.

2. Ambrose SA, Bridges MW, DiPietro M, Lovett MC, Norman MK. How Learning Works: Seven Research-Based Principles for Smart Teaching. San Francisco, CA: Jossey-Bass; 2010:96-97.

3. Kolb DA, Fry R. Toward an applied theory of experiential learning. In Cooper C, ed. Theories of Group Process. London, U.K.: John Wiley; 1975.

4. Gregorc AF. Gregorc Style Delineator: Development, Technical, and Administration Manual. Maynard, MA: Gregorc Associates, Inc.; 1984. 